\title{
Metrics for linking emissions of gases and aerosols to global precipitation changes
}

\author{
K. P. Shine ${ }^{1}$, R. P. Allan ${ }^{1}$, W. J. Collins ${ }^{1}$, and J. S. Fuglestvedt ${ }^{2}$ \\ ${ }^{1}$ Department of Meteorology, University of Reading, Reading, UK \\ ${ }^{2}$ Center for International Climate and Environmental Research - Oslo, Oslo, Norway \\ Correspondence to: K. P. Shine (k.p.shine@ reading.ac.uk)
}

Received: 13 March 2015 - Published in Earth Syst. Dynam. Discuss.: 2 April 2015

Revised: 21 July 2015 - Accepted: 13 August 2015 - Published: 31 August 2015

\begin{abstract}
Recent advances in understanding have made it possible to relate global precipitation changes directly to emissions of particular gases and aerosols that influence climate. Using these advances, new indices are developed here called the Global Precipitation-change Potential for pulse $\left(\mathrm{GPP}_{\mathrm{P}}\right)$ and sustained $\left(\mathrm{GPP}_{\mathrm{S}}\right)$ emissions, which measure the precipitation change per unit mass of emissions.

The GPP can be used as a metric to compare the effects of different emissions. This is akin to the global warming potential (GWP) and the global temperature-change potential (GTP) which are used to place emissions on a common scale. Hence the GPP provides an additional perspective of the relative or absolute effects of emissions. It is however recognised that precipitation changes are predicted to be highly variable in size and sign between different regions and this limits the usefulness of a purely global metric.

The GPPP and $\mathrm{GPP}_{\mathrm{S}}$ formulation consists of two terms, one dependent on the surface temperature change and the other dependent on the atmospheric component of the radiative forcing. For some forcing agents, and notably for $\mathrm{CO}_{2}$, these two terms oppose each other - as the forcing and temperature perturbations have different timescales, even the sign of the absolute GPPP and GPPS varies with time, and the opposing terms can make values sensitive to uncertainties in input parameters. This makes the choice of $\mathrm{CO}_{2}$ as a reference gas problematic, especially for the $\mathrm{GPP}_{\mathrm{S}}$ at time horizons less than about 60 years. In addition, few studies have presented results for the surface/atmosphere partitioning of different forcings, leading to more uncertainty in quantifying the GPP than the GWP or GTP.

Values of the GPPP and GPPS for five long- and short-lived forcing agents $\left(\mathrm{CO}_{2}, \mathrm{CH}_{4}, \mathrm{~N}_{2} \mathrm{O}\right.$, sulphate and black carbon - BC) are presented, using illustrative values of required parameters. The resulting precipitation changes are given as the change at a specific time horizon (and hence they are end-point metrics) but it is noted that the GPPS can also be interpreted as the time-integrated effect of a pulse emission. Using $\mathrm{CO}_{2}$ as a references gas, the GPP ${ }_{P}$ and $\mathrm{GPP}_{\mathrm{S}}$ for the non- $\mathrm{CO}_{2}$ species are larger than the corresponding GTP values. For $\mathrm{BC}$ emissions, the atmospheric forcing is sufficiently strong that the GPP is opposite in sign to the GTP. The sensitivity of these values to a number of input parameters is explored.

The GPP can also be used to evaluate the contribution of different emissions to precipitation change during or after a period of emissions. As an illustration, the precipitation changes resulting from emissions in 2008

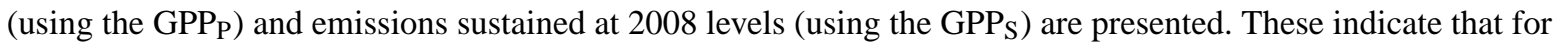
periods of 20 years (after the 2008 emissions) and 50 years (for sustained emissions at 2008 levels) methane is the dominant driver of positive precipitation changes due to those emissions. For sustained emissions, the sum of the effect of the five species included here does not become positive until after 50 years, by which time the global surface temperature increase exceeds $1 \mathrm{~K}$.
\end{abstract}




\section{Introduction}

A broad range of emissions of gases and aerosols influence climate, either directly or indirectly. That influence depends on the characteristics of the gases and aerosols, such as their lifetime, and their ability to influence the radiation budget. The conventional cause-and-effect chain links emissions to changes in concentrations, which then cause a radiative forcing with subsequent downstream effects on, for example, temperature, precipitation and sea level. By exploiting understanding of the characteristics of the gases and aerosols, in concert with simplified descriptions of the climate system, it is possible to develop simple methodologies that relate emissions directly to climate impacts, rather than having to explicitly account for the intermediate steps. Such methodologies have pedagogic value in making clearer the link between emissions (rather than, for example, concentration changes) and climate response and they also have potential applications. The purpose of this paper is to present a methodology that links global-mean precipitation directly to emissions of different gases and aerosols. This exploits recent advances in the understanding of how radiative forcing (RF) and temperature change influence precipitation change. The methodology presented here yields what we call the Global Precipitationchange Potential (GPP), which is the global-mean precipitation change per unit mass of emission. The GPP is presented for both pulse and sustained emissions.

The impact of climate change depends on more than just global temperature change. Hence the development of a methodology linking emissions directly to precipitation is attractive. However, projections from ensembles of climate model simulations show that precipitation change is much less amenable to a global representation than temperature change. The projections indicate that the average surface temperature response to increased concentrations of greenhouse gases later in this century is largely the same sign over the whole planet, the temperature changes are coherent on large spatial scales, and climate models largely agree on the pattern of temperature change, if not the absolute size (e.g., Knutti and Sendláček, 2013). By contrast, projected precipitation changes vary regionally in sign, are spatially much more variable and there is much less agreement between climate models on the patterns of response (e.g., Knutti and Sendláček, 2013). One part of the spatial pattern of precipitation change can be understood in quite simple terms, as being due to the enhanced convergence and divergence of moisture in a warmer and more moist atmosphere, assuming no change in the atmospheric flow that transports the moisture (Held and Soden, 2006). Other parts stem from changes in atmospheric circulation and surface water availability in response to forcing, and from internal variability; the response and variability differ between climate models, leading to the diverse model projections of precipitation change. Nevertheless, the global-mean precipitation response is coherent amongst these climate models such as that over the 21 st century, precipitation is projected to increase by about 1 to $3 \%$ per degree $\mathrm{C}$ of global-mean warming (e.g., M. Collins et al., 2013). This paper addresses the dependence of this global-mean component of precipitation change on the emitted species, as global-mean precipitation changes can be taken as being a useful indicator of the size of disturbance of the global hydrological cycle.

Section 2 presents a brief overview of emission metrics which are used to place emissions of different gases on some common (usually $\mathrm{CO}_{2}$-equivalent) scale, as this is one potential application of the GPP. Section 3 presents the simple conceptual model that is used to relate precipitation change to RF and temperature change, which are themselves related to emissions. Section 4 presents some illustrative examples of the GPP drawing values of key parameters from the literature. Section 5 then uses the methodology in the context of climate metrics, and compares it with more conventional metrics (the Global Warming Potential - GWP - and Global Temperature-change Potential - GTP). Section 6 presents an illustration of the use of the methodology for understanding the effects of emissions in an individual year (or sustained emissions from that year) on precipitation changes in or after that year - this illustrates the principal drivers of the precipitation change, given present-day emissions. Section 7 explores some aspects of the uncertainty in characterising the GPP and Sect. 8 discusses prospects for further developing the GPP, including possibilities for including more regionalscale information on precipitation response.

It is noted that Shindell et al. (2012) have demonstrated a link between radiative forcing (due to a variety of forcing mechanisms) in specific latitude bands to precipitation change in a number of selected regions; their precipitation change per unit radiative forcing was called a "Regional Precipitation Potential", which is distinct from the GPP framework presented here, where the precipitation change is directly related to emissions.

\section{The utility of emission metrics}

One potential application of the GPP is to place emissions of different species on a common scale, in a similar way to the GWP. The 100-year time-horizon GWP (GWP(100)) is used by the Kyoto Protocol to the United Nations' Framework Convention on Climate Change to place emissions of many relatively well-mixed non- $\mathrm{CO}_{2}$ greenhouse gases on a so-called " $\mathrm{CO}_{2}$-equivalent scale"; this is necessary for the type of multi-gas treaty that the Kyoto Protocol represents. Metrics such as the GWP can also be used in life-cycle assessment and carbon footprint studies, for assessing possible mitigation strategies, for example in particular economic sectors, and can extend beyond the gases included in the Kyoto Protocol (see e.g., Fuglestvedt et al., 2010; Deuber et al., 2014). 
The GWP characterises the RF in response to a pulse emission of a substance, integrated over some specified time horizon. It is normally expressed relative to the same quantity for an equal-mass emission of $\mathrm{CO}_{2}$. The GWP has enabled the multi-gas operation of the Kyoto Protocol but has also been the subject of criticism for some applications (e.g., Myhre et al. (2013), Pierrehumbert (2014) and references therein). This is partly because the use of time-integrated RF does not unambiguously relate to an impact of climate change (such as temperature change) and also because it contains value judgements (particularly the choice of time horizon) that cannot be rigorously justified for any particular application (Myhre et al., 2013).

Metrics that extend beyond time-integrated forcing have also been proposed. The GTP (e.g., Shine et al., 2007; Myhre et al., 2013) characterises the global-mean surface temperature change at some time after an emission. It may be more applicable to policies that aim to restrict temperature change below a given target level. The GTP is also subject to criticism and the need for value judgements when choosing time horizons (Myhre et al., 2013). Nevertheless the GTP (and its variants, such as the mean global temperature-change potential - e.g., Gillett and Matthews, 2010; Deuber et al., 2014 - and integrated temperature potential - e.g., Peters et al., 2011; Azar and Johansson, 2012) do at least extend to a parameter (temperature change) more obviously related to a climate change impact. Sterner et al. (2014) recently presented a metric for sea-level rise. Metrics can also be derived numerically on the basis of the contribution of an emission of a component at a given time, to temperature change (or other parameters) during some future period, as simulated by a simple climate model driven by a specific emissions scenario (e.g., Tanaka et al., 2009).

Metrics can also be extended to the economic effects of an emission (for example the Global Cost Potential and Global Damage Potential), by relating the metrics to costs and damages (e.g., Johansson, 2012) and in certain restrictive cases these can be shown to have equivalence to physically based metrics such as the GWP and GTP (e.g., Tol et al., 2012). One difficulty in such approaches is that the economic damage has to be represented in a highly-idealised form, as some simple function of, for example, global-mean temperature change. Conventional physical metrics can also be judged in an economic context (e.g., Reisinger et al., 2013; Strefler et al., 2014).

The GPP enables an additional and complementary methodology to existing methods for intercomparing the impacts of emissions of different species, and the impact of actual or proposed changes in those emissions.

\section{Simple conceptual model}

\subsection{Relationships between radiative forcing and changes in temperature and precipitation}

The simple conceptual model presented here originates from the analysis of simulated precipitation changes in response to increases in $\mathrm{CO}_{2}$ presented by Mitchell et al. (1987). This analysis was based around the fundamental controls on the energy balance of the troposphere, in which, to first order, the latent heating resulting from the net rate of condensation of water vapour (and hence precipitation) is balanced by net radiative cooling. The conceptual model has been further developed more recently, and extended to both multi-model assessments and other climate forcing (and feedback) mechanisms (e.g., Allen and Ingram, 2002; Takahashi, 2009; Andrews et al., 2010; Kvalevåg et al., 2013; Allan et al., 2014).

The framework starts with an expression of the globalmean atmospheric energy budget, whereby the net emission of radiation by the atmosphere (i.e., the atmospheric radiative divergence $\left(R_{\mathrm{d}}\right)$, which is the sum of the emission of longwave radiation by the atmosphere minus the atmospheric absorption of longwave and shortwave radiation) is balanced by the input of surface sensible $(\mathrm{SH})$ and latent $(\mathrm{LH})$ heat fluxes so that

$R_{\mathrm{d}}=\mathrm{LH}+\mathrm{SH}$

LH is directly related to the precipitation as, at the globalmean level, evaporation (and hence LH fluxes) and precipitation approximately balance.

In response to the imposition of an RF and subsequent changes in temperature, humidity and clouds, $R_{\mathrm{d}}$ will change. The latent heat change $\Delta \mathrm{LH}$ can then be written

$\Delta \mathrm{LH}=\Delta R_{\mathrm{d}}-\Delta \mathrm{SH}$

$\Delta \mathrm{LH}$ in $\mathrm{W} \mathrm{m}^{-2}$ can be converted to precipitation units of $\mathrm{mm}$ day $^{-1}$ by multiplication by $0.034(86400 \mathrm{~s}$ in a day divided by the latent heat of vaporisation, $L\left(2.5 \times 10^{6} \mathrm{~J} \mathrm{~kg}^{-1}\right.$ at $273.15 \mathrm{~K})$ ). There is some level of approximation in this conversion, as $L$ is temperature dependent and some precipitation falls as snow rather than rain, and hence the latent heat of sublimation would be more appropriate. The precipitation change could also be quoted in $\%$ of global-mean precipitation (about $2.68 \mathrm{~mm}$ day $^{-1}-$ e.g., Huffman et al., 2009).

$\Delta R_{\mathrm{d}}$ has two components. The first component is due directly to the RF mechanism which can change the absorption of shortwave radiation and/or the emission and absorption of longwave radiation. The conventional top-of-atmosphere radiative forcing (RF) can be written as the sum of a surface component $\left(\mathrm{RF}_{\mathrm{s}}\right)$ and an atmospheric component $\left(\mathrm{RF}_{\mathrm{a}}\right)$, and it is $\mathrm{RF}_{\mathrm{a}}$ that directly influences $\Delta R_{\mathrm{d}}$. Because values of $\mathrm{RF}$ are more readily available than $\mathrm{RF}_{\mathrm{a}}$ for a wide range of constituents, it is convenient to relate $\mathrm{RF}_{\mathrm{a}}$ to $\mathrm{RF}$ and so, following Allan et al. (2014), we define a parameter $f$ such that 
$\mathrm{RF}_{\mathrm{a}}=f \mathrm{RF}$. The parameter $f$ could be estimated directly from RF calculations using a radiative transfer code. However, here results from fixed-sea-surface-temperature climate model simulations (e.g., Andrews et al., 2010; Kvalevåg et al., 2013) are used; these have the advantage that they include the impact on $f$ of rapid adjustments of, for example, clouds. A disadvantage is that the results of such experiments are noisier, because of model internal variability, which can be particularly important for small forcings. Note that a fully consistent approach would adopt effective radiative forcings (ERF - see Myhre et al., 2013) rather than RF, and values of $f$ derived using ERFs. However, assessed values of ERFs are not available for many species and so, in common with Myhre et al., (2013), the metric values calculated here use RFs, but include a number of indirect chemical effects and some cloud effects, as noted in Sect. 4. The values of $f$ are based on one method of deriving ERFs and a possible reason for differences between $f$ values in Andrews et al. (2010) and Kvalevåg et al. (2013) (see Sect. 7) is that the fast tropospheric responses that distinguish RF from ERF differ between the models used in their studies.

The second component of $\Delta R_{\mathrm{d}}$ is due to the temperature change resulting from the RF, which leads to changes in emission of longwave radiation. This change is modified by feedbacks involving other radiatively important components such as water vapour and clouds (e.g., Takahashi, 2009; Previdi, 2010) which can also influence $\Delta R_{\mathrm{d}}$ via the absorption of shortwave radiation. Climate model simulations indicate that this component of $\Delta R_{\mathrm{d}}$ varies approximately linearly with changes in global-mean surface temperature $\Delta T_{\mathrm{S}}$ (e.g., Lambert and Webb, 2008; Previdi, 2010; O'Gorman et al., 2012).

$\triangle \mathrm{SH}$ in Eq. (2) is less well constrained. It also has two components, one due to the fast response to RF, which is independent of surface temperature change, and one due to surface temperature change. The fast response has been shown to be small for greenhouse gas forcings; Andrews et al. (2010) and Kvalevåg et al. (2013) show it to be typically less than $10 \%$ of $\Delta \mathrm{LH}$ for a doubling of $\mathrm{CO}_{2}$, although the size and sign can vary amongst models (Andrews et al., 2009). However, it can be much larger for other forcings (of order $50 \%$ of $\triangle \mathrm{LH}$ in the case of black carbon; Andrews et al., 2010; Kvalevåg et al., 2013). As noted by Takahashi (2009) and O'Gorman et al. (2012), an improved conceptual model could distinguish between $\Delta R_{\mathrm{d}}$ for the whole atmosphere and $\Delta R_{\mathrm{d}}$ for the atmosphere above the surface boundary layer; changes in $\Delta R_{\mathrm{d}}$ within the boundary layer seem more effective at changing SH (e.g., Ming et al., 2010) and hence less effective at changing LH. Here, following Thorpe and Andrews (2014), we assume the fast component $\Delta \mathrm{SH}$ to be small and neglect it, but more work in this area is clearly needed.

Lambert and Webb (2008), Previdi (2010), O'Gorman et al. (2012) and others show that while generally a smaller term, the surface temperature dependent part of $\Delta \mathrm{SH}$ has a similar dependency on $\Delta T_{\mathrm{s}}$ (at least in the multi-model mean) as $\Delta R_{\mathrm{d}}$. Hence it is convenient to combine the $\Delta T_{\mathrm{S}}$ -related changes in $R_{\mathrm{d}}$ and this component of SH in Eq. (2) into a single term dependent on $\Delta T_{\mathrm{S}}$ and separate out the $\mathrm{RF}$ term. Equation (2) then becomes, in precipitation units of $\mathrm{mm} \mathrm{day}^{-1}$,

$\Delta P=0.034\left(k \Delta T_{\mathrm{s}}-f \mathrm{RF}\right)$.

Despite its apparent simplicity, Eq. (3) has been shown by Thorpe and Andrews (2014) to reasonably well simulate future projections of global-mean precipitation change from a range of atmosphere-ocean general circulation models, albeit with a tendency to underestimate the multi-model mean. Uncertainty in the value of $f$ for all forcing agents (and possible inter-model variations in $f$ - see Sect. 7) inhibit a full assessment.

We refer to the $k \Delta T_{\mathrm{S}}$ term as the " $T$ term" and the $-f \mathrm{RF}$ term as the "RF term" although they could also be termed the "slow" and "fast" responses, respectively, which relates to the contrasting heat capacities and associated response timescales of the ocean and atmosphere. The balance between these two terms varies between climate forcing agents; as will be shown, they can act to either reinforce or oppose each other. Hence the same $\Delta T_{\mathrm{S}}$ from two different forcing agents can result in a different $\Delta P$.

Note the sign convention here. For the case of a positive $\mathrm{RF}$, since $k$ is positive, the effect of the $T$ term is to increase $R_{\mathrm{d}}$ as temperature increases - the increased radiative divergence then leads to a requirement for a greater latent heat flux (and hence an increase in precipitation) to maintain the tropospheric energy balance; this term provides the direct link between surface temperature change and precipitation change. If in this same case $f$ (and hence $\mathrm{RF}_{\mathrm{a}}$ ) is positive, then the RF term would oppose the $T$ term (as it would decrease rather than increase the radiative divergence) and act to suppress precipitation. Physically, in this case, there is less "demand" for latent heating to balance the tropospheric energy budget.

\subsection{Illustration for doubling of $\mathrm{CO}_{2}$}

As a simple example of the processes, consider the equilibrium response to a doubling of carbon dioxide, and take $k=2.2 \mathrm{~W} \mathrm{~m}^{-2} \mathrm{~K}^{-1}$ (consistent with the multi-model means in Previdi, 2010 and Thorpe and Andrews, 2014), $\mathrm{RF}_{2 \times \mathrm{CO}_{2}}=3.7 \mathrm{~W} \mathrm{~m}^{-2}$ (Myhre et al. (2013) who give the same value for the ERF) and $f=0.8$ (Andrews et al., 2010). The equilibrium precipitation change $\Delta P_{2 \times \mathrm{CO}_{2}}$ (in $\%$, assuming a global-mean precipitation of $2.68 \mathrm{~mm} \mathrm{day}^{-1}$ ), can then be written in terms of the equilibrium surface temperature change $\Delta T_{2 \times \mathrm{CO}_{2}}$ as

$\Delta P_{2 \times \mathrm{CO}_{2}}=2.79\left(\Delta T_{2 \times \mathrm{CO}_{2}}-1.35\right)$.

This equation shows that if $\Delta T_{2 \times \mathrm{CO}_{2}}=1.35 \mathrm{~K}$, which, via $\Delta T_{2 \times \mathrm{CO}_{2}}=\lambda \mathrm{RF}_{2 \times \mathrm{CO}_{2}}$, corresponds to a climate sensitivity 
$\lambda$ of $0.36 \mathrm{~K}\left(\mathrm{~W} \mathrm{~m}^{-2}\right)^{-1}, \Delta P_{2 \times \mathrm{CO}_{2}}$ would be zero. The slope of the line is $2.79 \% \mathrm{~K}^{-1}$. Such an expression fits well with the intercept and slope of the linear fit to equilibrium double$\mathrm{CO}_{2}$ experiments from a range of climate models found by Allen and Ingram (2002 - their Fig. 2). Hence Eq. (4) acts as a further validation of the utility of Eq. (3) for simulating global-mean precipitation change across climate models with varying parameterisations of, for example, convection, with climate sensitivities varying across the range from about 0.4 to $1.3 \mathrm{~K}\left(\mathrm{~W} \mathrm{~m}^{-2}\right)^{-1}$. The departures of individual models from this best fit could originate from differences in any of the values of $k, f, \mathrm{RF}_{2 \times \mathrm{CO}_{2}}$ assumed here, or in intermodel differences in the importance of the fast component of $\Delta \mathrm{SH}$ which is not accounted for here. The slope of the line also corresponds to hydrological sensitivity due only to the $T$ term, and is in good agreement with the multi-model mean derived by Thorpe and Andrews (2014).

Since more generally, $\Delta T_{\mathrm{eq}}=\lambda \mathrm{RF}_{\mathrm{eq}}$, Eq. (3) can also be written in a more general form for any $\Delta T_{\mathrm{eq}}$ (and hence $\mathrm{RF}_{\mathrm{eq}}$ ), so that the equilibrium change in precipitation $\Delta P_{\mathrm{eq}}$ (in \%) is given by

$\Delta P_{\text {eq }}=1.3 \Delta T_{\text {eq }}(k-f / \lambda)$.

This emphasizes that the offset between the $T$ and RF terms depends strongly on $\lambda$. Using a mid-range climate sensitivity of $0.8 \mathrm{~K}\left(\mathrm{~W} \mathrm{~m}^{-2}\right)^{-1}$, the RF term for $\mathrm{CO}_{2}$ offsets about $50 \%$ of the precipitation change that would result from the $T$ term alone. Considering the IPCC (2013) "likely" range for $\lambda$, which is 0.4 to $1.2 \mathrm{~K}$ ( $\left(\mathrm{W} \mathrm{m}^{-2}\right)^{-1}$, the RF term offsets the $T$ term by about $90 \%$ for low $\lambda$ and by $30 \%$ at high $\lambda$. The overall global-mean equilibrium hydrological sensitivity ( $\Delta P_{\text {eq }} / \Delta T_{\text {eq }}$ ) to $\mathrm{CO}_{2}$ forcing can be derived from Eq. (5) and varies from about $0.25 \% \mathrm{~K}^{-1}$ to $2 \% \mathrm{~K}^{-1}$ over this range of $\lambda$, which can be compared with the value of $2.79 \% \mathrm{~K}^{-1}$ due solely to the $T$ term.

\subsection{Application to emissions of a gas or aerosol}

To relate the understanding encapsulated in Eq. (3) to an emission of a gas or aerosol, we consider first the GPP for a pulse emission of unit mass of a gas at time $t=0$ and consider the precipitation change at time $\mathrm{H}$ after the emission. Following convention, we label this the Absolute GPP $\left(\mathrm{AGPP}_{\mathrm{P}}\right)$, which is presented here in units of mm day ${ }^{-1} \mathrm{~kg}^{-1}$.

The $T$ term in Eq. (3) becomes $k$ times the absolute GTPP $\left(\right.$ AGTP $\left._{\mathrm{P}}\right)$ (e.g., Shine et al., 2005). Assuming for small perturbations that RF is linear in the concentration of the emitted species, $x$, and that the perturbation decays exponentially with time constant $\tau_{x}$, then for a unit emission, the RF term is given by $-f_{x} A_{x} \exp \left(-H / \tau_{x}\right)$, where $A_{x}$ is the specific RF (in $\mathrm{W} \mathrm{m}^{-2} \mathrm{~kg}^{-1}$ ) of the emitted species. Hence the AGPP (in mm day ${ }^{-1} \mathrm{~kg}^{-1}$ ) is given by
$\operatorname{AGPP}_{\mathrm{P}}^{x}(H)=0.034\left(k \operatorname{AGTP}_{\mathrm{P}}^{x}(H)-f_{x} A_{x} \exp \left(-H / \tau_{x}\right)\right)$.

Since a perturbation of $\mathrm{CO}_{2}$ does not decay following a simple exponential (see e.g., Joos et al., 2013), the calculation of $\operatorname{AGPP}_{\mathrm{P}}^{\mathrm{CO}_{2}}(H)$ is slightly more involved - see the Appendix for more details.

The effect of a sustained emission of a unit mass of gas per year, from time $t=0$ can also be considered yielding a sustained AGPP (AGPPS). In this case, the $\operatorname{AGTP}_{S}$ (see Shine et al., 2005) can be used for the $T$ term and the RF term is now proportional to the time variation of the perturbation of the species to a step-perturbation (e.g., Fuglestvedt et al., 2010). The AGPP $_{S}$ is given by

$\operatorname{AGPP}_{\mathrm{S}}^{x}(H)=0.034\left(k \operatorname{AGTP}_{\mathrm{S}}^{x}(H)-f_{x} A_{x} \tau_{x}\left(1-\exp \left(-H / \tau_{x}\right)\right)\right)$,

which can also be expressed as a function of both AGTP $_{S}$ and AGWP as

$\operatorname{AGPP}_{\mathrm{S}}^{x}(H)=0.034\left(k \operatorname{AGTP}_{\mathrm{S}}^{x}(H)-f_{x} \operatorname{AGWP}^{x}(H)\right)$.

The calculation of $\operatorname{AGPP}_{\mathrm{S}}^{\mathrm{CO}_{2}}(H)$ is explained in the Appendix. Note that when $H$ is long compared to the timescale of the climate response (several hundred years in this case - see the Appendix) the $\operatorname{AGTP}_{S}^{x}(H)$ can itself be related to the $\operatorname{AGWP}_{\mathrm{P}}^{x}(H)$ (see e.g., Shine et al., 2005) which would simplify Eq. (8) further.

Here the $\mathrm{AGPP}_{\mathrm{P}}$ and $\mathrm{AGPP}_{\mathrm{S}}$ are used to calculate the $G^{G P P}$ and $G_{P P}$ relative to a reference gas, and following common practice for GWP and GTP, $\mathrm{CO}_{2}$ is used as that reference gas here, although difficulties with this choice will be noted. The GPP , relative to an equal mass emission of $\mathrm{CO}_{2}$, is then given by

$\operatorname{GPP}_{\mathrm{P}}^{x}(H)=\frac{\operatorname{AGPP}_{\mathrm{P}}^{x}(H)}{\operatorname{AGPP}_{\mathrm{P}}^{\mathrm{CO}_{2}}(H)}$,

with a similar expression for GPPS.

Note we have chosen to present the $\mathrm{AGPP}_{\mathrm{P}}$ and $\mathrm{AGPP}_{\mathrm{S}}$ as end-point metrics, i.e., as the effect at the time horizon $H$ of an emission at (or starting at) $t=0$. For some purposes, a time-integrated metric might give a useful perspective. Following Peters et al. (2011 - see in particular its Supplement) we note that time-integrated pulse metrics are mathematically equivalent to end-point metrics for sustained emissions. Hence, the $\mathrm{AGPP}_{\mathrm{S}}$ and $\mathrm{GPP}_{\mathrm{S}}$ can equally be interpreted as time-integrated forms of the $\mathrm{AGPP}_{\mathrm{P}}$ and $\mathrm{GPP}_{\mathrm{P}}$.

\section{Illustrative values for the absolute global precipitation-change potential}

In this section, illustrative calculations of the AGPP are presented. Values for gas lifetimes and $A_{x}$ are taken from Myhre et al. (2013) and are described in more detail in the Appendix. The AGTP calculation requires a representation of the surface temperature response, which depends 
on the climate sensitivity and rate of ocean heat uptake. We use the simple impulse response function in Boucher and Reddy (2008) (as used in Myhre et al. (2013) for GTP calculations). Details are given in the Appendix. Values of $f$, which describe the partitioning of the RF between surface and atmosphere are taken from Andrews et al. (2010) - these will likely be quite strongly model dependent, but for illustration purposes, they suffice. Some sensitivity tests to the representation of the impulse response function and $f$ are presented in Sect. 7. The calculations for $\mathrm{CH}_{4}$ and $\mathrm{N}_{2} \mathrm{O}$ emissions include indirect effects, the most prominent being their impact on ozone. Different values of $f$ should be used for each indirect component, but in the absence of robust assessments for these, the same value of $f$ is used for the indirect components as is used for the direct components.

\subsection{Well-mixed greenhouse gases}

Figure 1 shows the AGPP for $\mathrm{CO}_{2}, \mathrm{CH}_{4}$ and $\mathrm{N}_{2} \mathrm{O}$, for the total and the RF and $T$ terms individually, for a period of 100 years after the pulse emission. In Andrews et al. (2010), $f$ is larger for $\mathrm{CO}_{2}(0.8)$ than for methane $(0.5)$ because, for present-day concentrations, the lower opacity of the methane bands means that the surface feels more of the top-of-theatmosphere forcing than it does for $\mathrm{CO}_{2}$. Since $\mathrm{N}_{2} \mathrm{O}$ has a similar atmospheric opacity to $\mathrm{CH}_{4}$, it is hypothesized that surface-atmosphere partitioning of the RF also behaves in a similar way to $\mathrm{CH}_{4}$ and so the value of $f$ for $\mathrm{N}_{2} \mathrm{O}$ is also taken to be 0.5 ; further work is needed to establish this. Hence, from Eq. (3), the degree of offset between the RF and $T$ terms is larger for $\mathrm{CO}_{2}$ than for $\mathrm{CH}_{4}$ and $\mathrm{N}_{2} \mathrm{O}$.

Figure 1a for $\mathrm{CO}_{2}$ illustrates the general behaviour. For a pulse emission, the size of the RF term is maximised at the time of emission, as this is when the concentration is largest, and then decays as the perturbation decays. The $T$ term is dictated by the timescale of the response of the surface temperature to the forcing. The characteristic temperature response to a pulse forcing (e.g., Shine et al., 2005) is an initial increase in $T$, as the thermal inertia of the surface means it takes time to respond to the forcing, reaching a maximum, followed by a decrease that is controlled by the timescales of both the decay of the pulse and the climate response. For the first 5 years, the $\mathrm{CO}_{2}$ precipitation response is negative as the RF term dominates, after which the $T$ term dominates, but the total is approximately $50 \%$ of the $T$ term. The long perturbation timescales mean that the effect on precipitation persists for more than 100 years after an emission, as does the competition between the $T$ and RF terms.

$\mathrm{N}_{2} \mathrm{O}$ has a lifetime of the order of a century and its AGPPP (Fig. 1b) is qualitatively similar to $\mathrm{CO}_{2}$ but the $T$ term dominates, because $f$ is smaller. As $\mathrm{CH}_{4}$ is much shorter lived, its behaviour is somewhat different. As the pulse, and the associated RF, has disappeared by about year 40 , after this time the $\mathrm{AGPP}_{\mathrm{P}}$ is determined by the $T$ term only.
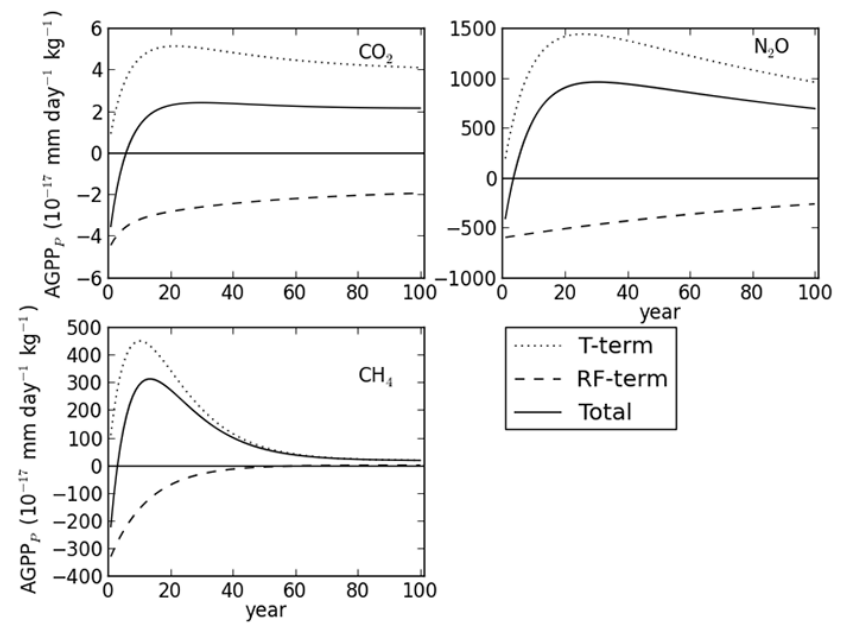

Figure 1. $\mathrm{AGPP}_{\mathrm{P}}$ for $1 \mathrm{~kg}$ pulse emissions of $\mathrm{CO}_{2}, \mathrm{~N}_{2} \mathrm{O}$ and $\mathrm{CH}_{4}$. The $T$ term and RF term refer to the first and second terms on the right hand side of Eq. (3) respectively, and the Total is the sum of these.

\subsection{Short-lived species}

The AGPP is illustrated for two short-lived species, sulphate and black carbon (BC) aerosols. For both cases, the radiative efficiency and lifetime values from Myhre et al. (2013) are used and given in the Appendix; for these illustration purposes only the sulphate direct effects are included, and the $\mathrm{BC}$ values include some aerosol-cloud interaction and surface albedo effects. In terms of the surface-atmosphere partitioning of RF, these are two contrasting cases. For sulphate, the Andrews et al. (2010) model results indicate an $f$ value less than 0.01 in magnitude and is assumed here to be zero; this indicates that essentially all of the top-ofthe-atmosphere forcing reaches the surface. By contrast, Andrews et al. (2010) find that for $\mathrm{BC}, f$ is 2.5 , so that $\mathrm{RF}_{\mathrm{a}}$ is much greater than RF; the surface forcing is of opposite sign to $R F$ and $R F_{a}$ as the surface is deprived of energy, while the atmosphere gains energy. As will be discussed further in Sect. 7, there are considerable uncertainties in these values, especially for $\mathrm{BC}$, where both $\mathrm{RF}$ and $f$ depend strongly on the altitude of the BC. Nevertheless, the values used here suffice to illustrate a number of important points.

Figure 2 shows the AGPPP $_{P}$ for $\mathrm{BC}$ and sulphate. As both are very short-lived (weeks) compared to the greenhouse gases, their RF term decays to zero within a year (and hence is not visible on Fig. 2), and it is only the thermal inertia of the climate system that enables them to influence temperature (and hence precipitation) beyond this time period.

An alternative perspective is provided for the sustainedemissions case. In this case, because the $\mathrm{BC}$ and sulphate perturbations persist, so too does the influence of the RF term on precipitation. Figure 3 shows the $\mathrm{AGPP}_{\mathrm{S}}$ for $\mathrm{CO}_{2}, \mathrm{BC}$ and sulphate. For $\mathrm{CO}_{2}$, the long timescales of the $\mathrm{CO}_{2}$ perturbation mean that both the RF term and $T$ term increase through- 

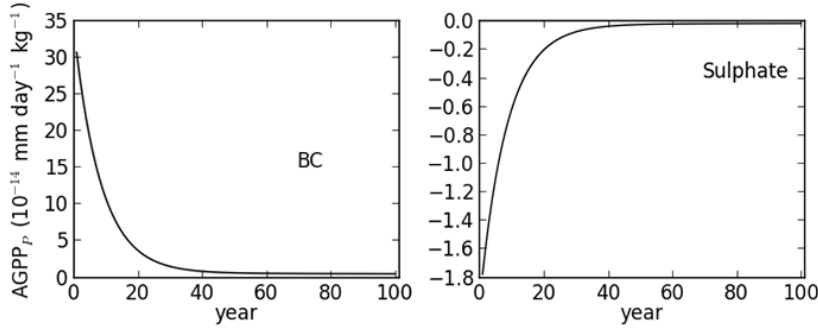

Figure 2. $\mathrm{AGPP}_{\mathrm{P}}$ for $1 \mathrm{~kg}$ pulse emissions of black carbon (BC) and sulphate. Note that the RF term in Eq. (3) is negligible for such short-lived gases, except at time horizons less than a few weeks, and only the total is shown.

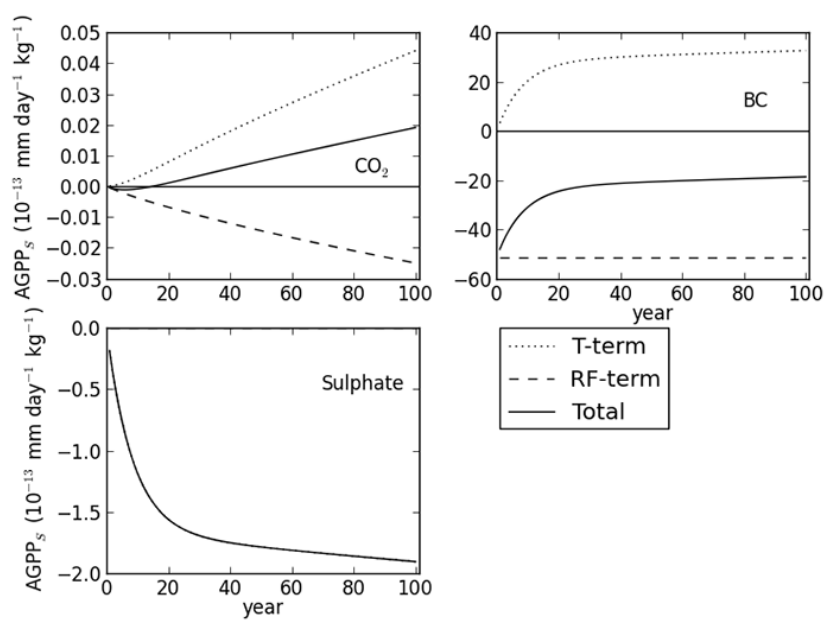

Figure 3. $\mathrm{AGPP}_{\mathrm{S}}$ for $1 \mathrm{~kg} \mathrm{yr}^{-1}$ sustained emissions of $\mathrm{CO}_{2}, \mathrm{BC}$ and sulphate. The $T$ term and RF term refer to the first and second terms on the right hand side of Eq. (3) respectively, and the Total is the sum of these. For sulphate, the RF term is assumed to be zero (see text) and so only the Total is shown.

out the 100-year period shown. At short time horizons, the RF term dominates, leading to suppression of global precipitation, but after about 15 years, the $T$ term starts to dominate, and the $\mathrm{AGPP}_{\mathrm{S}}$ becomes positive. For BC, the impact of the large RF term is dramatic. It is strongly negative and constant with time (because of the short lifetime), while the $T$ term is positive and increases until the temperature is almost in equilibrium with the RF. This counteracts the impact of the RF term, but the total nevertheless remains negative throughout. For sulphate, because $f$ is assumed to be zero, the total remains equal to the $T$ term.

\section{The GPP relative to $\mathrm{CO}_{2}$}

Absolute GPP values were presented in Sect. 4. In this section we normalize the GPP values to the effects of the reference gas $\mathrm{CO}_{2}$ to provide a relative measure, using Eq. (9) and its equivalent for sustained emissions.

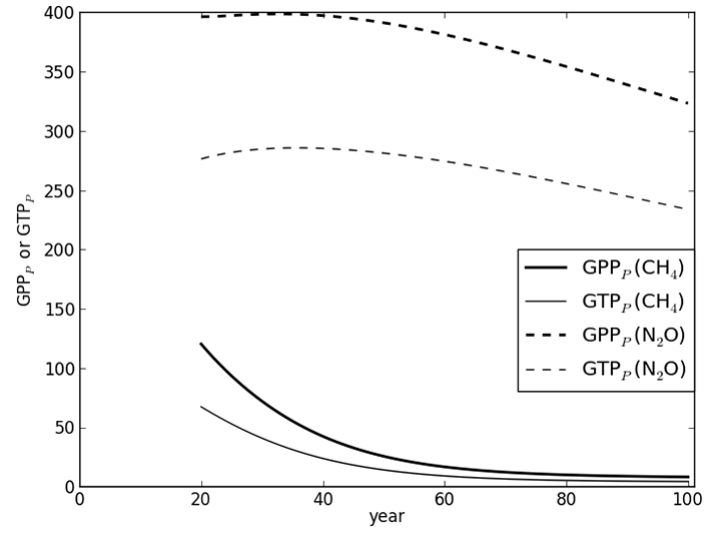

Figure 4. $\mathrm{GPP}_{\mathrm{P}}$ (in bold) and $\mathrm{GTP}_{\mathrm{P}}$ for $1 \mathrm{~kg}$ pulse emissions of $\mathrm{N}_{2} \mathrm{O}$ and $\mathrm{CH}_{4}$ relative to a $1 \mathrm{~kg}$ pulse emission of $\mathrm{CO}_{2}$.

\subsection{Well-mixed greenhouse gases}

Figure 4 shows the GPPP for $\mathrm{N}_{2} \mathrm{O}$ and $\mathrm{CH}_{4}$; for comparison, the GTPP is also shown. Note that the plots start at $H=20$ years, as the time at which the AGPP $\mathrm{P}_{\mathrm{P}}$ crosses the zero axis differs slightly amongst the gases, and this results in a singularity in Eq. (9). For $\mathrm{N}_{2} \mathrm{O}$, the GPPP is at least 300 times greater than $\mathrm{CO}_{2}$ on all timescales shown, and, per unit emission, is more than $40 \%$ more effective at changing precipitation than temperature (as given by the GTP $\mathrm{P}_{\mathrm{P}}$ ), compared to $\mathrm{CO}_{2}$. This is because the RF term is less effective at muting the $T$ term for $\mathrm{N}_{2} \mathrm{O}$ 's $\mathrm{GPP}_{\mathrm{P}}$ than is the case for $\mathrm{CO}_{2}$. For $\mathrm{CH}_{4}$ the difference between the GPP and GTPP is most marked in an absolute sense at shorter time horizons, when the GPP of methane is affected most by the RF term; the GPP and the absolute difference with the GTP decline at longer timescales when it is entirely due to the difference between the $\mathrm{AGTP}_{\mathrm{P}}$ and $\mathrm{AGPP}_{\mathrm{P}}$ for $\mathrm{CO}_{2}$.

Table 1 presents the values of all absolute metrics used here for $\mathrm{CO}_{2}$ and Table 2 presents the values of the GWP, GTPP $_{\mathrm{P}}$ and $\mathrm{GPP}_{\mathrm{P}}$ for $H$ of 20 and 100 years; these time horizons are chosen for illustrative purposes, rather than being indicative that they have special significance, except insofar as 100 years is used for the GWP within the Kyoto Protocol (e.g., Myhre et al., 2013). For $\mathrm{CH}_{4}$, the $\mathrm{GPP}_{\mathrm{P}}(20)$ is $50 \%$ larger than the $\operatorname{GWP}_{\mathrm{P}}(20)$ and almost double the $\operatorname{GTP}_{\mathrm{P}}(20)$ mostly because of the larger effect of the RF term on the $\mathrm{AGPP}_{\mathrm{P}}$ for $\mathrm{CO}_{2}$. The time-integrated nature of the GWP means that it is much higher than the GTPP and GPPP at 100 years, while the $G_{P P}$ remains about double the GTP $_{P}$. The GPP for $\mathrm{N}_{2} \mathrm{O}$ is $25-50 \%$ higher than the GWP and GTP $_{\mathrm{P}}$ at both values of $H$, again because of the larger effect of the RF term on the AGPPP for $\mathrm{CO}_{2}$.

\subsection{Short-lived species}

Figure 5 shows the GPPP and GTPP for $\mathrm{BC}$ and sulphate. As noted in Sect. 4.2, the radical difference in their values of $f$ 
Table 1. Absolute metrics, AGWP, AGTP $, \mathrm{AGTP}_{\mathrm{S}}, \mathrm{AGPP}_{\mathrm{P}}$ and $\mathrm{AGPP}_{\mathrm{S}}$ for $\mathrm{CO}_{2}$ at time horizons of 20 and 10 years, which are chosen for illustrative purposes. The first and second sets of AGPP values use the $\mathrm{CO}_{2} f$ factor from Andrews et al. (2010) and Kvalevåg et al. (2013), respectively (see Table A1).

\begin{tabular}{llcc}
\hline & & \multicolumn{2}{c}{ Time horizon (years) } \\
\cline { 3 - 4 } & Unit & 20 & 100 \\
\hline AGWP & $\mathrm{W} \mathrm{m}^{-2} \mathrm{~kg}^{-1} \mathrm{yr}$ & $2.50 \times 10^{-14}$ & $9.19 \times 10^{-14}$ \\
AGTPP & $\mathrm{K} \mathrm{kg}^{-1}$ & $6.85 \times 10^{-16}$ & $5.48 \times 10^{-16}$ \\
AGTP $_{\mathrm{S}}$ & $\mathrm{K} \mathrm{kg}^{-1} \mathrm{yr}$ & $1.05 \times 10^{-14}$ & $5.90 \times 10^{-14}$ \\
AGPPP $_{\text {(Andrews) }}$ & $\mathrm{mm} \mathrm{day}^{-1} \mathrm{~kg}^{-1}$ & $2.27 \times 10^{-17}$ & $2.13 \times 10^{-17}$ \\
AGPP $_{\mathrm{S}}$ (Andrews) & $\mathrm{mm} \mathrm{day}^{-1} \mathrm{~kg}^{-1} \mathrm{yr}$ & $1.05 \times 10^{-16}$ & $1.91 \times 10^{-15}$ \\
AGPPP $_{\text {(Kvalevåg) }}$ & $\mathrm{mm} \mathrm{day}^{-1} \mathrm{~kg}^{-1}$ & $2.99 \times 10^{-17}$ & $2.63 \times 10^{-17}$ \\
AGPP $_{\mathrm{S}}$ (Kvalevåg) & $\mathrm{mm} \mathrm{day}^{-1} \mathrm{~kg}^{-1} \mathrm{yr}$ & $2.75 \times 10^{-16}$ & $2.53 \times 10^{-15}$ \\
\hline
\end{tabular}

Table 2. The GWP, GTP and GPP , relative to $\mathrm{CO}_{2}$, for pulse emissions of four species at time horizons of 20 and 100 years, which are chosen for illustrative purposes. The absolute values of metrics for $\mathrm{CO}_{2}$ are given in Table 1 .

\begin{tabular}{lrrrrrr}
\hline & GWP $(20)$ & GWP $(100)$ & $\operatorname{GTP}_{\mathrm{P}}(20)$ & $\mathrm{GTP}_{\mathrm{P}}(100)$ & $\mathrm{GPP}_{\mathrm{P}}(20)$ & $\mathrm{GPP}_{\mathrm{P}}(100)$ \\
\hline $\mathrm{CH}_{4}$ & 84 & 28 & 67 & 4.3 & 120 & 8.1 \\
$\mathrm{~N}_{2} \mathrm{O}$ & 263 & 264 & 276 & 234 & 396 & 325 \\
Sulphate & -141 & -38 & -41 & -5.28 & -92 & -10.1 \\
Black carbon & 2415 & 657 & 701 & 91 & 1580 & 173 \\
\hline
\end{tabular}

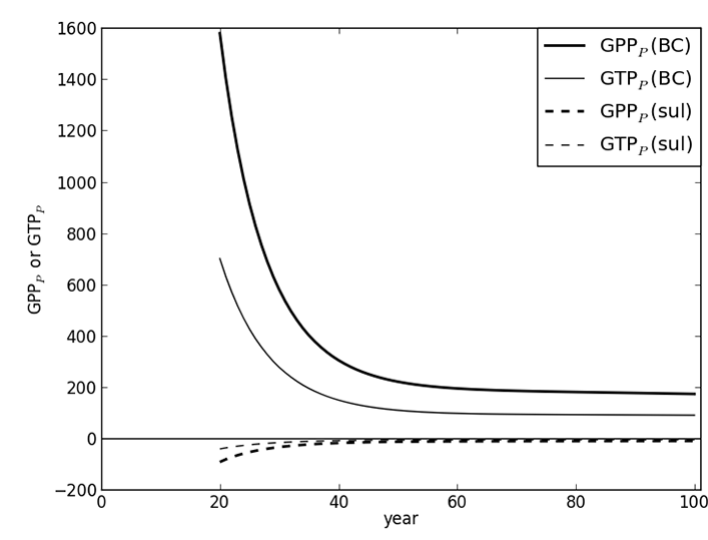

Figure 5. GPP (in bold) and $\mathrm{GTP}_{\mathrm{P}}$ for $1 \mathrm{~kg}$ pulse emissions of $\mathrm{BC}$ and sulphate relative to a $1 \mathrm{~kg}$ pulse emission of $\mathrm{CO}_{2}$.

(2.5 for black carbon, 0 for sulphate) has no impact on the $\mathrm{AGPP}_{\mathrm{P}}$ for $\mathrm{BC}$ and sulphate beyond very short timescales. Because of this, in Fig. 5, the only difference between the $G_{P P}$ and $G_{P} P_{P}$ comes from the influence of the RF term on $\mathrm{AGPP}_{\mathrm{P}}^{\mathrm{CO}_{2}}$, and on an equal emissions basis both shortlived species are, relative to $\mathrm{CO}_{2}$, more effective at changing precipitation than temperature - this is also shown in Table 2.

Figure 6 shows the $\mathrm{GPP}_{\mathrm{S}}$, comparing it with the $\mathrm{GTP}_{\mathrm{S}}$. For sulphate, the difference between the $\mathrm{GPP}_{\mathrm{S}}$ and $\mathrm{GTP}_{\mathrm{S}}$ originates entirely from the effect of the RF term on $\mathrm{AGPP}_{\mathrm{S}}^{\mathrm{CO}_{2}}$, because of the assumption that $f$ is zero. For BC they differ dramatically - whilst both $\mathrm{BC}$ and $\mathrm{CO}_{2}$ cause a warming, so

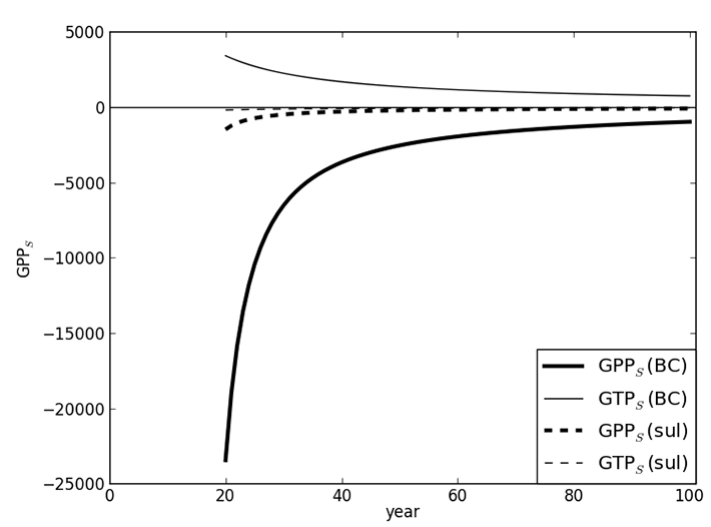

Figure 6. GPP (in bold) and $\mathrm{GTP}_{\mathrm{S}}$ for $1 \mathrm{~kg} \mathrm{yr}^{-1}$ sustained emissions of $\mathrm{BC}$ and sulphate relative to a $1 \mathrm{~kg} \mathrm{yr}^{-1}$ sustained emission of $\mathrm{CO}_{2}$.

that $\operatorname{GTP}_{\mathrm{S}}$ is positive, their impact on precipitation is opposite, and the BC GPPS is negative.

Table 3 presents values of the $\mathrm{GTP}_{\mathrm{S}}$ and $\mathrm{GPP}_{\mathrm{S}}$ for $H=20$ and 100 years, including the values for $\mathrm{CH}_{4}$ and $\mathrm{N}_{2} \mathrm{O}$ for completeness. The GPPS values at 20 years are particularly influenced by the fact that the $\mathrm{AGPP}_{\mathrm{S}}$ for $\mathrm{CO}_{2}$ is relatively small at this time, due to the strong cancellation between the $T$ and RF terms. At both values of $H, G P P_{S}$ values are higher in magnitude than the corresponding $\mathrm{GTP}_{\mathrm{S}}$ values for all non- $\mathrm{CO}_{2}$ components considered here. 

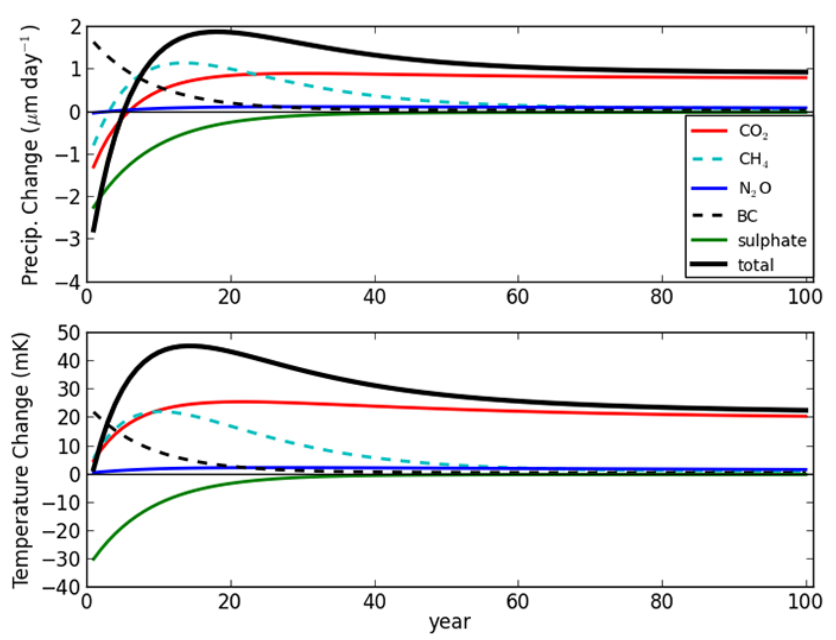

Figure 7. Precipitation change, in $\mu \mathrm{m} \mathrm{day}^{-1}$ (top panel), and temperature change, in $\mathrm{mK}$, (bottom panel) in the years after 2008, following a pulse emission in 2008, calculated using the AGPPP and AGTP $_{P}$ and using estimated emissions of the species in 2008.

\section{Precipitation response to realistic emissions}

To illustrate a further usage of the $\mathrm{AGPP}_{\mathrm{P}}$ and $\mathrm{AGPP}_{\mathrm{S}}$, Figs. 7 and 8 apply them to 2008 emissions, to examine the consequences of the emissions of the five example species on precipitation. Figure 8.33 of Myhre et al. (2013) presents a similar calculation applying the AGTPP and shows that the five species used here are the dominant emissions for determining temperature change; hence it was felt useful to also present the total effect of the five emissions in the figures. Emissions are taken from Table 8.SM.18 of Myhre et al. (2013) and reproduced in Table A1. For reference, the corresponding values using the $\mathrm{AGTP}_{\mathrm{P}}$ and $\mathrm{AGTP}_{\mathrm{S}}$ are also shown in the figures.

Figure 7 shows the impact of the 2008 emissions, emitted as a single pulse, on global precipitation and temperature change in subsequent years. While the emissions of $\mathrm{CH}_{4}$, sulphate and $\mathrm{BC}$ are 2 to 4 orders of magnitude smaller than those of $\mathrm{CO}_{2}$, in the early years after the emission, their effects are competitive with $\mathrm{CO}_{2}$ because of the size of the GPPP $_{P}$ and GTP ; emissions of $\mathrm{N}_{2} \mathrm{O}$ are small enough that, despite its large $\mathrm{GPP}_{\mathrm{P}}$, its absolute contribution remains low throughout. Because of the differing compensations between the $T$ and $\mathrm{RF}$ terms for $\mathrm{CO}_{2}$ and $\mathrm{CH}_{4}$, their relative importance differs quite significantly between precipitation and temperature. Methane's contribution to precipitation change is less negative or more positive than that of $\mathrm{CO}_{2}$ until about 20 years; it exceeds the $\mathrm{CO}_{2}$ contribution by a factor of 2 at about 10 years, and remains $25 \%$ of the $\mathrm{CO}_{2}$ effect even at 50 years. For temperature, the contributions are approximately the same until 10 years, after which the $\mathrm{CO}_{2}$ contribution dominates, being about 7 times larger by 50 years. For the two aerosol components, the GPPP is unaffected by
Table 3. The GTPS and $\mathrm{GPP}_{\mathrm{S}}$, relative to $\mathrm{CO}_{2}$, for sustained emissions of four other species at time horizons of 20 and 100 years, which are chosen for illustrative purposes. The absolute values of metrics for $\mathrm{CO}_{2}$ are given in Table 1 .

\begin{tabular}{lrrrr}
\hline & $\mathrm{GTP}_{\mathrm{S}}(20)$ & $\mathrm{GTP}_{\mathrm{S}}(100)$ & $\mathrm{GPP}_{\mathrm{S}}(20)$ & $\mathrm{GPP}_{\mathrm{S}}(100)$ \\
\hline $\mathrm{CH}_{4}$ & 93 & 31.5 & 357 & 49.6 \\
$\mathrm{~N}_{2} \mathrm{O}$ & 256 & 267 & 846 & 401 \\
Sulphate & -199 & -43.2 & -1490 & -100 \\
Black carbon & 3410 & 741 & -23500 & -979 \\
\hline
\end{tabular}
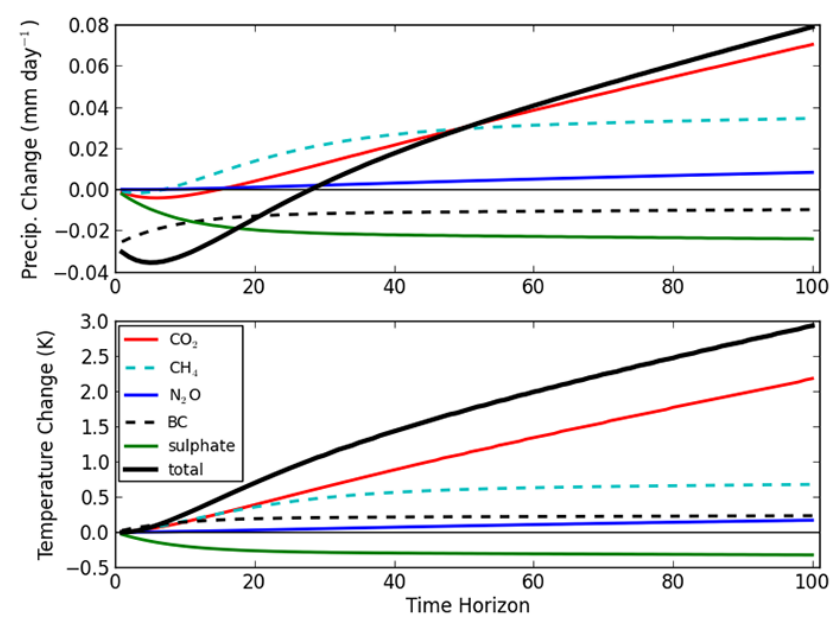

Figure 8. Precipitation change, in $\mathrm{mm} \mathrm{day}^{-1}$ (top panel), and temperature change, in K, (bottom panel) in the years after 2008, assuming constant emissions at 2008 levels, calculated using the $\mathrm{AGPP}_{\mathrm{S}}$ and $\mathrm{AGTP}_{\mathrm{S}}$ and using estimated emissions of the species in 2008 .

the RF term (because the RF due to a pulse emission of a short-lived gas declines rapidly - see Sect. 4) but their importance for precipitation relative to $\mathrm{CO}_{2}$ is enhanced, because the RF term acts to suppress the effect of $\mathrm{CO}_{2}$ on precipitation change. Thus, for example, the $\mathrm{BC}$ effect on precipitation is larger than $\mathrm{CO}_{2}$ out to year 10 , compared to year 4 for temperature.

Figure 8 shows the effect of assuming sustained emissions at 2008 levels. Although not a plausible future scenario (since, for example, emissions of greenhouse gases are at present continuing to rise) it provides a useful baseline experiment to assess the relative roles of current emissions when their atmospheric burdens are replenished each year. As expected from the AGPPS values, the role of the shortlived species differs considerably from the pulse case, as the $\mathrm{RF}$ term remains active - in the case of precipitation, BC's effect is now negative throughout. Until about 30 years, the net effect of all five emissions is a reduction of precipitation, after which the warming due to $\mathrm{CH}_{4}$ and $\mathrm{CO}_{2}$ is sufficient for their $T$ terms to overwhelm the reduction caused by sulphate (due to its $T$ term) and BC (due to its RF term). This near-term reduction of precipitation is also seen in the re- 
Table 4. The GPPP and GPP , relative to $\mathrm{CO}_{2}$, for pulse emissions of four other species at time horizons of 20 and 100 years, which are chosen for illustrative purposes, using the values of surface-atmosphere partitioning of radiative forcing from Kvalevåg et al. (2013). The two black carbon values are, respectively, using values of $f$ for a model-derived vertical profile for present-day emissions and assuming that the present-day burden is placed entirely at $550 \mathrm{hPa}$. The absolute values of metrics for $\mathrm{CO}_{2}$ are given in Table 1.

\begin{tabular}{lrrrr}
\hline & $\operatorname{GPP}_{\mathrm{P}}(20)$ & $\operatorname{GPP}_{\mathrm{P}}(100)$ & $\mathrm{GPP}_{\mathrm{S}}(20)$ & $\mathrm{GPP}_{\mathrm{S}}(100)$ \\
\hline $\mathrm{CH}_{4}$ & 101 & 6.6 & 187 & 44.4 \\
$\mathrm{~N}_{2} \mathrm{O}$ & 370 & 303 & 486 & 367 \\
Sulphate & -70 & -8.2 & -741 & -94.0 \\
Black Carbon & 1200 & 141 & $-36600,-87400$ & $-3740,-9250$ \\
\hline
\end{tabular}

sults of Allan et al. (2014), where the precipitation changes are driven directly by forcings and temperatures (rather than by emissions, as is the case here). By contrast, the temperature effect is positive after year 1 . Perhaps most marked is the role of $\mathrm{CH}_{4}$. It is the dominant driver of positive precipitation change until about year 50 and even after 100 years its effect is about $50 \%$ of that due to $\mathrm{CO}_{2}$. This differs from temperature, where the $\mathrm{CO}_{2}$ effect is greatest after 15 years and 3 times larger by 100 years. Figure 8 also illustrates the extent to which the sulphate and $\mathrm{BC}$ emissions are opposing the precipitation increase due to the greenhouse gases, at large values of $H$; those components would respond relatively quickly to any changes in emissions.

While these are clearly idealised applications of uncertain metrics, they nevertheless illustrate their potential utility for assessing the relative importance over time of different emissions on global precipitation change. The approach could be extended to past or possible future emission profiles, by convolving the time-dependent emissions with the GPPP and $\mathrm{GPP}_{\mathrm{S}}$ values.

\section{Sensitivities and uncertainties}

There are many uncertainties and sensitivities in the calculation of metrics such as assumptions about the background state (which can affect $A_{x}$ and $\tau_{x}$ ), and the impulse response function for $\mathrm{CO}_{2}$ (see e.g., Fuglestvedt et al., 2010; Joos et al., 2013; Myhre et al., 2013). Two sensitivities are explored. First, the impulse response model for surface temperature change used here (see Sect. 4) is a fit to output from experiments with one particular climate model with its own particular climate sensitivity. Olivié et al. (2012) present similar fits derived from 17 different climate models, or model variants - the fits shown in Table 5 of Olivié et al. (2012) are used, along with the Boucher and Reddy (2008) fit used in Sect. 4, and cover a wide range of climate sensitivities $\left(0.49\right.$ to $\left.1.06 \mathrm{~K}\left(\mathrm{~W} \mathrm{~m}^{-2}\right)^{-1}\right)$ and timescales of climate response, although we note that model uncertainty range may not fully straddle the true uncertainty range. Olivié and Peters (2013) used these fits to explore the sensitivity of the GTP calculations. Figure 9 shows the mean and standard de-
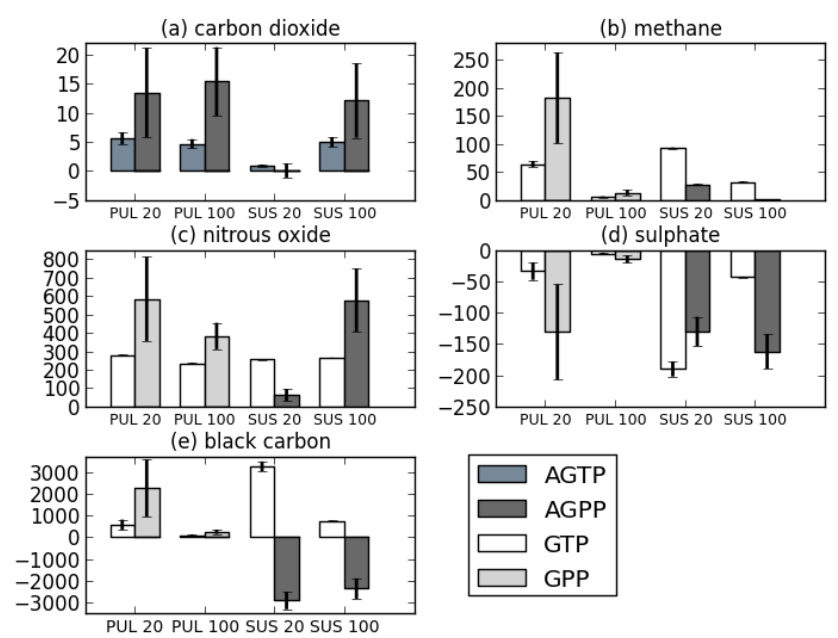

Figure 9. Mean and standard deviations of the AGTP, AGPP, GTP and GPP for both pulse (PUL) and sustained (SUS) emissions for time horizons of 20 and 100 years (which are chosen for illustrative purposes), using 18 different representations of the impulse response function for temperature change. (a) AGTP and AGPP for carbon dioxide, for both pulse and sustained emissions, and then $\mathrm{GTP}_{\mathrm{P}}, \mathrm{GPP}_{\mathrm{P}}, \mathrm{GTP}_{\mathrm{S}}$ and $\mathrm{AGPP}_{\mathrm{S}}$ for (b) methane, (c) nitrous oxide, (d) sulphate and (e) black carbon. For $\mathrm{CO}_{2}$ the units are $10^{-16} \mathrm{~K} \mathrm{~kg}^{-1}$ for $\mathrm{AGTP}_{\mathrm{P}}$, $10^{-14} \mathrm{~K} \mathrm{~kg}^{-1} \mathrm{yr}$ for $\mathrm{AGTP}_{\mathrm{S}}, 10^{-18} \mathrm{~mm} \mathrm{day}^{-1} \mathrm{~kg}^{-1}$ for $\mathrm{AGPP}_{\mathrm{P}}$ and $10^{-16} \mathrm{~mm} \mathrm{day}^{-1} \mathrm{~kg}^{-1} \mathrm{yr}$ for AGPPS. The AGPP for all other gases are in $10^{-15} \mathrm{~mm} \mathrm{day}^{-1} \mathrm{~kg}^{-1} \mathrm{yr}$.

viation of the pulse and sustained GTP and GPP derived using these 18 different representations.

Considering the absolute pulse metrics for $\mathrm{CO}_{2}$, Fig. 9a shows that the AGTPP is only moderately sensitive (with a coefficient of variation (cv) of about $20 \%$ ) to model choice. By contrast the cv is about 60 and $40 \%$ for the $\operatorname{AGPP}_{\mathrm{P}}(20)$ and $\operatorname{AGPP}_{\mathrm{P}}(100)$, respectively. This is because the $T$ term is highly sensitive to the choice of impulse response model, whilst the RF term is independent; hence the degree of compensation between these two terms varies amongst these models. The GTP is most sensitive for short-lived species and this uncertainty is amplified for the GPPP, by up to a factor of 2 for the $\operatorname{GPP}_{\mathrm{P}}(100)$ for sulphate (Fig. 9d). By con- 
trast, for the longer-lived species the uncertainty in the GTPP and $\mathrm{GPP}_{\mathrm{P}}$ differ greatly - for $\mathrm{N}_{2} \mathrm{O}$ (Fig. 9c), the $\mathrm{cv}$ for $\mathrm{GTP}_{\mathrm{P}}$ values is only a percent or so, but is typically $40 \%$ for the $\mathrm{GPP}_{\mathrm{P}}$, as both the numerator and denominator in Eq. (9) are impacted by compensations in the $T$ and RF terms to different degrees at different times.

The $\mathrm{GPP}_{\mathrm{S}}$ is more sensitive because even the sign of the $\mathrm{AGPP}_{\mathrm{S}}^{\mathrm{CO}_{2}}$ is not well constrained at 20 years (Fig. 9a). Roughly half of the impulse response models yield positive values and half negative ones, with two near zero, because of the differing degrees of compensation between the $T$ and RF terms. The value of $H$ at which the $\mathrm{AGPP}_{\mathrm{S}}^{\mathrm{CO}_{2}}$ is zero varies from 11 to 61 years amongst the models. (For comparison, for the $\mathrm{AGPP}_{\mathrm{P}}^{\mathrm{CO}_{2}}$, the corresponding range is 4 to 13 years.) In these circumstances, it becomes difficult to compare the $\mathrm{GPP}_{\mathrm{S}}$ values as they vary wildly from model to model (from -18000 to 24000 for the $\operatorname{GPP}_{\mathrm{S}}(20)$ for $\mathrm{N}_{2} \mathrm{O}$ ) and for this reason the $\mathrm{AGPP}_{\mathrm{S}}$ is presented in Fig. 9. Even the $\mathrm{AGPP}_{\mathrm{S}}^{\mathrm{CO}_{2}}(100)$ values vary by over an order of magnitude across the 18 models. In general, the uncertainties in the $\mathrm{AGPP}_{\mathrm{S}}$ exceed those in the AGTP ; this is most marked in the case of $\mathrm{N}_{2} \mathrm{O}$, where the GTPS is almost insensitive to the choice of impulse response model, as the effect of this choice on the $\mathrm{AGTP}_{\mathrm{S}}$ for $\mathrm{CO}_{2}$ and $\mathrm{N}_{2} \mathrm{O}$ is almost the same.

The second sensitivity explored here is to the assumed values of $f$ by replacing the Andrews et al. (2010) values by those from Kvalevåg et al. (2013) (see Table A1). Where available, we use the values of $f$ from the larger forcing perturbations given by Kvalevåg et al. (2013) as these give a clearer signal. For BC, Kvalevåg et al. (2013) present a range of values, for perturbations at different altitudes - for example they find a value of $f$ of 6.2 (for 10 times the modelderived vertical profile of $\mathrm{BC}$ in response to present-day emissions) and 13 (when 10 times the present-day burden is placed entirely at $550 \mathrm{hPa}$ ); these can be compared to the Andrews et al. (2010) value of 2.5. The difference results mostly from the semi-direct effect of BC and clouds; when $\mathrm{BC}$ is entirely placed at certain pressures $(750$ and $650 \mathrm{hPa})$, Kvalevåg et al.'s (2013) results indicate that $f$ is particularly poorly constrained, because RF is close to zero, while $\mathrm{RF}_{\mathrm{a}}$ is large and positive. This is an example of where casting Eq. (3) directly in terms of $\mathrm{RF}_{\mathrm{a}}$ rather than $\mathrm{RF}$ would be advantageous (see Sect. 3). It should be noted that this sensitivity test concerns the impact of $\mathrm{BC}$ altitude on $f$ rather than on $\tau_{x}$ and $A_{x}$.

Table 1 shows the $\mathrm{AGPP}_{\mathrm{P}}$ and $\mathrm{AGPP}_{\mathrm{S}}$ for $\mathrm{CO}_{2}$ and Table 4 shows the GPPP and GPPS; these should be compared with the appropriate columns in Tables 2 and 3 (the GWP, $\mathrm{GTP}_{\mathrm{P}}$ and $\mathrm{GTP}_{\mathrm{S}}$ are unaffected by $f$ ). For the $\mathrm{GPP}_{\mathrm{P}}$ for $\mathrm{CH}_{4}$ and $\mathrm{N}_{2} \mathrm{O}$, the effect of changing the $f$ values is rather modest (10-20\%) because changes in the numerator and denominator of Eq. (9) compensate to some extent. For BC and sulphate, changes are entirely dependent on the change in $\mathrm{AGPP}_{\mathrm{P}}^{\mathrm{CO}_{2}}$, as the change in $f$ factor has little influence (see
Sect. 4.2) and hence changes are correspondingly larger (20$30 \%)$.

The $\operatorname{AGPP}_{\mathrm{S}}^{\mathrm{CO}_{2}}(20)$ (Table 1) is rather sensitive to the change in $f$ because of the degree of compensation between the $T$ and RF terms, and increases by more than a factor of 2 (Table 1). This is the dominant reason why the $\operatorname{GPP}_{S}(20)$ for $\mathrm{N}_{2} \mathrm{O}$ and $\mathrm{CH}_{4}$ decrease by about a factor of 2 . The changes at 100 years are much smaller, nearer $10 \%$. The AGPPS for the short-lived species are, unlike the AGPP , now affected by the change in $f$. Table 5 shows the effect on the sulphate $\operatorname{GPP}_{S}(20)$ to be about a factor of 2, while the $\operatorname{GPP}_{S}(100)$ is little affected. By contrast, the $\mathrm{GPP}_{\mathrm{S}}$ for black carbon at both time horizons depends significantly on the altitude of the black carbon perturbation.

\section{Discussion and conclusions}

This paper has used a simple, but demonstrably useful, conceptual model of the drivers of global-mean precipitation change in response to the imposition of a radiative forcing, to relate precipitation change directly to emissions. The $\mathrm{GPP}_{\mathrm{P}}$ and $\mathrm{GPP}_{\mathrm{S}}$ metrics illustrate the interplay between the two drivers (the atmospheric component of the radiative forcing, and the surface temperature change) for different forcings, at different time horizons, and for both pulse and sustained emissions. The $\mathrm{GPP}_{\mathrm{P}}$ and $\mathrm{GPP}_{\mathrm{S}}$ are given as the change at a specific time horizon (and hence are end-point metrics). There may be climate effects related to the total change in precipitation over time for which an integrated metric would be appropriate, so it is useful to note that the $\mathrm{GPP}_{\mathrm{S}}$ can also be interpreted as the time-integrated $\mathrm{GPP}_{\mathrm{P}}$.

It has been shown that relative to $\mathrm{CO}_{2}$, the pulse and sustained GPP values for the non- $\mathrm{CO}_{2}$ species examined here are larger than the corresponding GTP values, because the $\mathrm{CO}_{2}$ GPP is the sum of two quite strongly opposing terms. Further, for black carbon emissions, while they act to warm the climate system, they also act to reduce global-mean precipitation; while this has been clear from the modelling literature for some time, the present work shows how the perspective is different for pulse and sustained emissions. The reduction of precipitation is driven entirely by the radiative forcing component and since, for pulse emissions of shortlived species this falls away on timescales of weeks, it is only apparent on longer timescales for the sustained perspective. This is an example of how the perturbation design can have a large impact on the calculated response.

The evaluation of precipitation metrics assumes that the parameters required for the simple conceptual model are available, and in particular the partitioning of radiative forcing between surface and atmosphere. Only a rather limited number of model studies of this partitioning are currently available, and there are significant differences amongst these and particular sensitivity to the altitude of absorbing aerosol (e.g., Ming et al., 2010; Kvalevåg et al., 2013). 
In addition, further development of the simple conceptual model (particularly to account for fast changes in the sensible heat flux) would be beneficial, once understanding improves, as would a fully consistent usage of effective radiative forcings. The ongoing Precipitation Driver Response Model Intercomparison Project (PDRMIP) (http://cicero.uio. no/PDRMIP/) should provide important information on the utility of the conceptual model and of the degree of robustness of the surface-atmosphere partitioning amongst a range of climate models for a number of radiative forcing mechanisms. Clearly further studies for a wider range of forcing agents are also needed and indeed casting Eq. (3) directly in terms of the atmospheric component of radiative forcing $\mathrm{RF}_{\mathrm{a}}$ (rather than top-of-atmosphere radiative forcing) would be desirable if values of $\mathrm{RF}_{\mathrm{a}}$ become more readily available.

It is not suggested that the new metrics could replace conventional emissions metrics such as the GWP and GTP in climate policy or emission trading contexts, but they do provide a useful additional perspective for assessing the effects of emissions; they particularly help to emphasise where the impact on precipitation differs significantly from that on temperature or forcing. One difficulty in its application is that conventional metrics generally use $\mathrm{CO}_{2}$ as a reference gas. For precipitation change, the forcing and surface temperature components oppose each other, which means that the effect of $\mathrm{CO}_{2}$ emissions on precipitation can be zero (at least in the global-mean) at short time horizons for both pulse and sustained emissions. This is clearly undesirable for a reference gas, and it has also been shown that the timing of this zero point is rather sensitive to the particular parameters used in its calculation. Hence absolute metrics may be more instructive. By applying the absolute metrics to a specific illustrative case (emissions in 2008, either as a pulse, or sustained indefinitely) the importance of methane in influencing the global-mean precipitation change is highlighted - using the default model parameters here, in the sustained 2008 emissions case, the precipitation change from methane exceeds that from $\mathrm{CO}_{2}$ for about 50 years, By contrast, for temperature, the effect of $\mathrm{CO}_{2}$ emissions is almost immediately at least comparable to, or stronger than, methane.
It has been stressed that use of global-mean precipitation change as a measure of impact has difficulties, because predicted future changes differ in sign between regions - the global-mean is a small residual of these opposing more localised changes and hence it only gives rather general guidance on the effect of different drivers on the changing hydrological cycle. Nevertheless, some of the regional pattern of response can be understood as a generic and coherent response to temperature change. Increases and decreases in precipitation are largely reflective of an amplification of precipitation minus evaporation fields, primarily explained by increasing concentrations of water vapour with warming (as expected from the Clausius-Clapeyron equation); this leads to systematic increases and decreases in precipitation depending on the region (e.g., Held and Soden, 2006; Liu and Allan, 2013).

The approach here could be enhanced to a more regional level of response by either using a simple pattern-scaling approach (whereby the pattern of predicted precipitation change scales with the global-mean) or, better, to derive a regional variation that accounts for the different effects of the forcing and temperature response on precipitation change (Good et al., 2012). The patterns emerging from such an approach would likely depend significantly on which climate model was used to derive them. In addition, such patterns would be needed for all the primary forcing agents. For shortlived emissions, it is known that even global-mean metrics such as the GWP and GTP depend on the emission location (e.g., Fuglestvedt et al., 2010) - this will also be true for the precipitation metrics. Metrics can also be posed in terms of the regional response to regional emissions. For example, W. J. Collins et al. (2013) employed the Regional Temperature Potential proposed by Shindell (2012) whereby a matrix is produced that characterises the effect of RFs in a set of given regions on the temperature change in a set of given regions; a similar approach could be taken using the Regional Precipitation Potential proposed by Shindell et al. (2012).

In spite of the difficulties in quantifying the precipitation metrics given present knowledge of the driving parameters, the framework presented here adds a useful extra dimension to simple tools that are currently available for assessing the impact of emissions of different gases and particulates. 


\section{Appendix A}

The impulse response function, $R(t)$, for a pulse emission of $\mathrm{CO}_{2}$ is assumed to be of the form

$R(t)=a_{o}+\sum_{j=1}^{3} a_{j} \exp \left(-\frac{t}{\alpha_{j}}\right)$,

where the parameters used here follow Myhre et al. (2013), with $a_{o}=0.2173, a_{1}=0.2240, a_{2}=0.2824, a_{3}=0.2763$ and $\alpha_{1}=394.4$ years, $\alpha_{2}=36.54$ years and $\alpha_{3}=4.304$ years.

The impulse response function for global-mean surface temperature in Sects. 4 to 6 is taken from Boucher and Reddy (2008) and is of the form

$R(t)=\sum_{i=1}^{2} \frac{c_{i}}{d_{i}} \exp \left(-\frac{t}{d_{i}}\right)$,

with $c_{1}=0.631 \mathrm{~K}\left(\mathrm{~W} \mathrm{~m}^{-2}\right)^{-1}, c_{2}=0.429 \mathrm{~K}\left(\mathrm{~W} \mathrm{~m}^{-2}\right)^{-1}$ and $d_{1}=8.4$ years and $d_{2}=409.5$ years. The equilibrium climate sensitivity for this function is $1.06 \mathrm{~K}\left(\mathrm{~W} \mathrm{~m}^{-2}\right)^{-1}$, equivalent to an equilibrium surface temperature change for a doubling of $\mathrm{CO}_{2}$ of about $3.9 \mathrm{~K}$. Additional impulse response functions are used in Sect. 7, with alternative values of $c_{i}$ and $d_{i}$.

To derive the $\operatorname{AGPP}_{P}$ in Eq. (6), for species for which the perturbation decays exponentially with a single timeconstant $\tau_{x}$, an expression for AGTP $_{\mathrm{P}}$ is required. For a species with a specific RF $A_{x}$ and using Eq. (A2) this is given by (see, for example, Fuglestvedt et al., 2010)

$\operatorname{AGTP}_{\mathrm{P}}^{x}(t)=A_{x} \tau_{x} \sum_{i=1}^{2} \frac{c_{i}}{\tau_{x}-d_{i}}\left(\exp \left(-t / \tau_{x}\right)-\exp \left(-t / d_{i}\right)\right)$.

This equation does not apply in the case where $\tau_{x}=d_{i}$; the appropriate expression is given in Shine et al. (2005) for this case, which has to be modified for the two-term form of Eq. (A2).

For the case of $\mathrm{CO}_{2}$, where the decay of a pulse is given by Eq. (A1), the AGTPP is given by (see, for example, Fuglestvedt et al., 2010)

$$
\begin{aligned}
& \operatorname{AGTP}_{\mathrm{P}}^{\mathrm{CO}_{2}}(t)=A_{\mathrm{CO}_{2}}\left[a_{o} \sum_{i=1}^{2} c_{i}\left(1-\exp \left(-\frac{t}{d_{i}}\right)\right)\right. \\
& \left.+\sum_{i=1}^{2} c_{i} \sum_{j=1}^{3} \frac{a_{j} \alpha_{j}}{\alpha_{j}-d_{i}}\left(\exp \left(-t / \alpha_{j}\right)-\exp \left(-t / d_{i}\right)\right)\right],
\end{aligned}
$$

and the exponential in the second term on the right-hand side of Eq. (6) is replaced by Eq. (A1).

To derive the AGPP $\mathrm{S}$ in Eq. (7), the GTPS for non- $\mathrm{CO}_{2}$ species is given by (by rearranging the expression in Shine et al., 2005 following Peters et al., 2011)

$$
\begin{aligned}
\operatorname{AGTP}_{\mathrm{S}}^{x}(t) & =A_{x} \tau_{x}\left[\sum _ { i = 1 } ^ { 2 } \frac { c _ { i } } { \tau _ { x } - d _ { i } } \left(\tau_{x}\left(1-\exp \left(-t / \tau_{x}\right)\right)\right.\right. \\
& \left.\left.-d_{i}\left(1-\exp \left(-t / d_{i}\right)\right)\right)\right]
\end{aligned}
$$

and again the case where $\tau_{x}=d_{i}$ is given in Shine et al. (2005), which has to be modified for the two-term form of Eq. (A2).

The calculation of the $\mathrm{AGPP}_{\mathrm{S}}$ for $\mathrm{CO}_{2}$ requires the $\mathrm{AGTP}_{\mathrm{S}}$ and is given by

$$
\begin{aligned}
\operatorname{AGTP}_{\mathrm{S}}^{\mathrm{CO}_{2}}(t) & =\sum_{i=1}^{2} A_{\mathrm{CO}_{2}} c_{i}\left[a_{o}\left(t-d_{i}\left(1-\exp \left(-t / d_{i}\right)\right)\right)\right. \\
& +\sum_{j=1}^{3} \frac{\alpha_{j} a_{j}}{\alpha_{j}-d_{i}}\left(\alpha_{j}\left(1-\exp \left(-t / \alpha_{i}\right)\right)\right. \\
& \left.\left.-d_{i}\left(1-\exp \left(-t / d_{i}\right)\right)\right)\right]
\end{aligned}
$$

and also $\mathrm{AGWP}^{\mathrm{CO}}$, for the second term on the right hand side of Eq. (7) which is

$\mathrm{AGWP}^{\mathrm{CO}_{2}}(t)=A_{\mathrm{CO}_{2}}\left(a_{o} t+\sum_{j=1}^{3} a_{j} \alpha_{j}\left(1-\exp \left(-\frac{t}{\alpha_{j}}\right)\right)\right)$.

The parameters used for the five different species employed here are presented in Table A1. 
Table A1. Parameter values used for each species included in calculations. All values are taken from Myhre et al. (2013), unless otherwise stated, and the $\mathrm{CH}_{4}$ and $\mathrm{N}_{2} \mathrm{O}$ values of $A_{x}$ include the indirect effects described there.

\begin{tabular}{llllrc}
\hline & $\begin{array}{l}A_{x} \\
\left(\mathrm{~W} \mathrm{~m}^{-2} \mathrm{~kg}^{-1}\right)\end{array}$ & $\begin{array}{l}\tau_{x} \\
\text { (years) }\end{array}$ & $\begin{array}{l}f \text { (Andrews } \\
\text { et al. 2010) }\end{array}$ & $\begin{array}{r}f \text { (Kvalevåg } \\
\text { et al. 2013) }\end{array}$ & $\begin{array}{c}2008 \\
\text { emissions } \\
(\mathrm{kg})\end{array}$ \\
\hline $\mathrm{CO}_{2}$ & $1.76 \times 10^{-15}$ & See text & 0.8 & 0.6 & $3.69 \times 10^{13}$ \\
$\mathrm{CH}_{4}$ & $2.11 \times 10^{-13}$ & 12.4 & 0.5 & 0.3 & $3.64 \times 10^{11}$ \\
$\mathrm{~N}_{2} \mathrm{O}$ & $3.57 \times 10^{-13}$ & 121.0 & 0.5 & 0.3 & $1.07 \times 10^{10}$ \\
Sulphate & $-3.2 \times 10^{-10}$ & 0.011 & 0.0 & -0.4 & $1.27 \times 10^{11}$ \\
Black carbon & $3.02 \times 10^{-9}$ & 0.02 & 2.5 & $6.2,13.0$ & $5.31 \times 10^{9}$ \\
\hline
\end{tabular}


Author contributions. K. P. Shine conceived the idea of the emissions metrics for precipitation, through conversations with R. P. Allan, performed the calculations and led the writing. R. P. Allan, W. J. Collins and J. S. Fuglestvedt provided major critical input to the drafts, including ideas on adjusting the emphasis of the paper and on possible applications of the metrics.

Acknowledgements. We acknowledge funding from the European Commission, under the ECLIPSE (Evaluating the Climate and Air Quality Impacts of Short-Lived Pollutants) Project (Grant Agreement 282688) and thank other ECLIPSE partners for their encouragement and input to this work. We are grateful to Katsumasa Tanaka, an anonymous reviewer and the Editor, Steven Smith, for their helpful comments, and for suggestions and input from participants in PDRMIP.

Edited by: S. Smith

\section{References}

Allan, R. P., Liu, C. L., Zahn, M., Lavers, D. A., Koukouvagias, E., and Bodas-Salcedo, A.: Physically consistent responses of the global atmospheric hydrological cycle in models and observations, Surv. Geophys., 35, 533-552, doi:10.1007/s10712-0129213-z, 2014

Allen, M. R. and Ingram, W. J.: Constraints on future changes in climate and the hydrologic cycle, Nature, 419, 224-232, doi:10.1038/nature01092, 2002.

Andrews, T., Forster, P. M., and Gregory, J. M.: A surface energy perspective on climate change, J. Climate, 22, 2570-2557, doi:10.1175/2008JCLI2759.1, 2009.

Andrews, T., Forster, P. M., Boucher, O., Bellouin, N., and Jones, A.: Precipitation, radiative forcing and global temperature change, Geophys. Res. Lett., 37, L14701, doi:10.1029/2010g1043991, 2010.

Azar, C. and Johansson, D. J. A.: On the relationship between metrics to compare greenhouse gases - the case of IGTP, GWP and SGTP, Earth Syst. Dynam., 3, 139-147, doi:10.5194/esd-3-1392012, 2012.

Boucher, O. and Reddy, M. S.: Climate trade-off between black carbon and carbon dioxide emissions, Energy Policy, 36, 193-200, doi:10.1016/j.enpol.2007.08.039, 2008.

Collins, M., Knutti, R., Arblaster, J., Dufresne, J.-L., Fichefet, T., Friedlingstein, P., Gao, X., Gutowski, W. J., Johns, T., Krinner, G., Shongwe, M., Tebaldi, C., Weaver, A. J., and Wehner, M.: Long-term Climate Change: Projections, Commitments and Irreversibility, in: Climate Change 2013: The Physical Science Basis, Contribution of Working Group I to the Fifth Assessment Report of the Intergovernmental Panel on Climate Change, edited by: Stocker, T. F., Qin, D., Plattner, G. K., Tignor, M., Allen, S. K., Boschung, J., Nauels, A., Xia, Y., Bex, V., and Midgley, P. M., Cambridge University Press, Cambridge, United Kingdom and New York, NY, USA, 659-740, 2013.

Collins, W. J., Fry, M. M., Yu, H., Fuglestvedt, J. S., Shindell, D. T., and West, J. J.: Global and regional temperature-change potentials for near-term climate forcers, Atmos. Chem. Phys., 13, 2471-2485, doi:10.5194/acp-13-2471-2013, 2013.
Deuber, O., Luderer, G., and Sausen, R.: $\mathrm{CO}_{2}$ equivalences for short-lived climate forcers, Climatic Change, 122, 651-664, doi:10.1007/s10584-013-1014-y, 2014.

Fuglestvedt, J. S., Shine, K. P., Berntsen, T., Cook, J., Lee, D. S., Stenke, A., Skeie, R. B., Velders, G. J. M., and Waitz, I. A.: Transport impacts on atmosphere and climate: Metrics, Atmos. Environ., 44, 4648-4677, doi:10.1016/j.atmosenv.2009.04.044, 2010.

Gillett, N. P. and Matthews, H. D.: Accounting for carbon cycle feedbacks in a comparison of the global warming effects of greenhouse gases, Environ. Res. Lett., 5, 034011, doi:10.1088/1748-9326/5/3/034011, 2010.

Good, P., Ingram, W., Lambert, F. H., Lowe, J. A., Gregory, J. M., Webb, M. J., Ringer, M. A., and Wu, P. L.: A step-response approach for predicting and understanding non-linear precipitation changes, Clim. Dynam., 39, 2789-2803, doi:10.1007/s00382012-1571-1, 2012.

Held, I. M. and Soden, B. J.: Robust responses of the hydrological cycle to global warming, J. Climate, 19, 5686-5699, doi:10.1175/jcli3990.1, 2006.

Huffman, G. J., Adler, R. F., Bolvin, D. T., and Gu, G. J.: Improving the global precipitation record: GPCP Version 2.1, Geophys. Res. Lett., 36, L17808, doi:10.1029/2009g1040000, 2009.

IPCC: Climate Change 2013: The Physical Science Basis, Contribution of Working Group I to the Fifth Assessment Report of the Intergovernmental Panel on Climate Change, Cambridge University Press, Cambridge, UK and New York, NY, USA, 1535 pp., 2013.

Johansson, D. J. A.: Economics- and physical-based metrics for comparing greenhouse gases, Climatic Change, 110, 123-141, doi:10.1007/s10584-011-0072-2, 2012.

Joos, F., Roth, R., Fuglestvedt, J. S., Peters, G. P., Enting, I. G., von Bloh, W., Brovkin, V., Burke, E. J., Eby, M., Edwards, N. R., Friedrich, T., Frölicher, T. L., Halloran, P. R., Holden, P. B., Jones, C., Kleinen, T., Mackenzie, F. T., Matsumoto, K. Meinshausen, M., Plattner, G.-K., Reisinger, A., Segschneider, J., Shaffer, G., Steinacher, M., Strassmann, K., Tanaka, K., Timmermann, A., and Weaver, A. J.: Carbon dioxide and climate impulse response functions for the computation of greenhouse gas metrics: a multi-model analysis, Atmos. Chem. Phys., 13, 2793 2825, doi:10.5194/acp-13-2793-2013, 2013.

Knutti, R. and Sendláček, J.: Robustness and uncertainties in the new CMIP5 climate model projections, Nat. Clim. Change, 3, 369-373, doi:10.1038/nclimate1716, 2013.

Kvalevåg, M. M., Samset, B. H., and Myhre, G.: Hydrological sensitivity to greenhouse gases and aerosols in a global climate model, Geophys. Res. Lett., 40, 1432-1438, doi:10.1002/grl.50318, 2013.

Lambert, F. H. and Webb, M. J.: Dependency of global mean precipitation on surface temperature, Geophys. Res. Lett., 35, L16706, doi:10.1029/2008g1034838, 2008.

Liu, C. L. and Allan, R. P.: Observed and simulated precipitation responses in wet and dry regions $1850-2100$, Environ. Res. Lett., 8, 034002, doi:10.1088/1748-9326/8/3/034002, 2013.

Ming, Y., Ramaswamy, V., and Persad, G.: Two opposing effects of absorbing aerosols on global-mean precipitation, Geophys. Res. Lett., 37, L13701, doi:10.1029/2010g1042895, 2010.

Mitchell, J. F. B., Wilson, C. A., and Cunnington, W. M.: On $\mathrm{CO}_{2}$ climate sensitivity and model dependence of results, Q. J. Roy. 
Meteorol. Soc., 113, 293-322, doi:10.1002/qj.49711347517, 1987.

Myhre, G., Shindell, D., Bréon, F.-M., Collins, W., Fuglestvedt, J., Huang, J., Koch, D., Lamarque, J.-F., Lee, D., Mendoza, B., Nakajima, T., Robock, A., Stephens, G., Takemura, T., and Zhang, H.: Anthropogenic and Natural Radiative Forcing, in: Climate Change 2013: The Physical Science Basis, Contribution of Working Group I to the Fifth Assessment Report of the Intergovernmental Panel on Climate Change, edited by: Stocker, T. F., Qin, D., Plattner, G. K., Tignor, M., Allen, S. K., Boschung, J., Nauels, A., Xia, Y., Bex, V., and Midgley, P. M., Cambridge University Press, Cambridge, UK and New York, NY, USA, 659740, 2013

O’Gorman, P. A., Allan, R. P., Byrne, M. P., and Previdi, M.: Energetic constraints on precipitation under climate change, Surv. Geophys., 33, 585-608, doi:10.1007/s10712-011-9159-6, 2012.

Olivié, D. J. L. and Peters, G. P.: Variation in emission metrics due to variation in $\mathrm{CO}_{2}$ and temperature impulse response functions, Earth Syst. Dynam., 4, 267-286, doi:10.5194/esd-4-267-2013, 2013.

Olivié, D. J. L., Peters, G. P., and Saint-Martin, D.: Atmosphere response time scales estimated from AOGCM experiments, J. Climate, 25, 7956-7972, doi:10.1175/jcli-d-11-00475.1, 2012.

Peters, G. P., Aamaas, B., Berntsen, T., and Fuglestvedt, J. S.: The integrated global temperature change potential (iGTP) and relationships between emission metrics, Environ. Res. Lett., 6, 044021, doi:10.1088/1748-9326/6/4/044021, 2011.

Pierrehumbert, R. T.: Short-lived climate pollution, Ann. Rev. Earth Planet. Sci., 42, 341-379, doi:10.1146/annurev-earth-060313054843, 2014.

Previdi, M.: Radiative feedbacks on global precipitation, Environ. Res. Lett., 5, 025211, doi:10.1088/1748-9326/5/2/025211, 2010.

Reisinger, A., Havlik, P., Riahi, K., van Vliet, O., Obersteiner, M., and Herrero, M.: Implications of alternative metrics for global mitigation costs and greenhouse gas emissions from agriculture, Climatic Change, 117, 677-690, doi:10.1007/s10584-012-05933, 2013.
Shindell, D. T.: Evaluation of the absolute regional temperature potential, Atmos. Chem. Phys., 12, 7955-7960, doi:10.5194/acp12-7955-2012, 2012.

Shindell, D. T., Voulgarakis, A., Faluvegi, G., and Milly, G.: Precipitation response to regional radiative forcing, Atmos. Chem. Phys., 12, 6969-6982, doi:10.5194/acp-12-6969-2012, 2012.

Shine, K. P. Fuglestvedt, J. S., Hailemariam, K., and Stuber, N.: Alternatives to the global warming potential for comparing climate impacts of emissions of greenhouse gases, Climatic Change, 68, 281-302, doi:10.1007/s10584-005-1146-9, 2005.

Shine, K. P., Berntsen, T. K., Fuglestvedt, J. S., Skeie, R. B., and Stuber, N.: Comparing the climate effect of emissions of shortand long-lived climate agents, Philos. T. Roy. Soc. A, 365, 19031914, doi:10.1098/rsta.2007.2050, 2007.

Sterner, E., Johansson, D. A., and Azar, C.: Emission metrics and sea level rise, Climatic Change, 127, 335-351, doi:10.1007/s10584-014-1258-1, 2014.

Strefler, J., Luderer, G., Aboumahboub, T., and Kriegler, E.: Economic impacts of alternative greenhouse gas emission metrics: a model-based assessment, Climatic Change, 125, 319-331, doi:10.1007/s10584-014-1188-y, 2014.

Takahashi, K.: The global hydrological cycle and atmospheric shortwave absorption in climate models under $\mathrm{CO}_{2}$ forcing, J. Climate, 22, 5667-5675, doi:10.1175/2009jcli2674.1, 2009.

Tanaka, K., O’Neill, B. C., Rokityanskiy, D., Obersteiner, M., and Tol, R. S. J.: Evaluating global warming potentials with historical temperature, Climatic Change, 96, 443-466, doi:10.1007/s10584-009-9566-6, 2009.

Thorpe, L. and Andrews, T.: The physical drivers of historical and 21 st century global precipitation changes, Environ. Res. Lett., 9, 064024, doi:10.1088/1748-9326/9/6/064024, 2014.

Tol, R. S. J., Berntsen, T. K., O’Neill, B. C., Fuglestvedt, J. S., and Shine, K. P.: A unifying framework for metrics for aggregating the climate effect of different emissions, Environ. Res. Lett., 7, 044006, doi:10.1088/1748-9326/7/4/044006, 2012. 